\title{
PRESENTACIÓN DE ESTE NÚMERO
}

Como en ocasiones anteriores tenemos el agrado de presentar el número 4 de RSEUS -Revista Sudamericana de Educación, Universidad y Sociedad- de la Facultad de Ciencias de la Educación de la Universidad de la Empresa, revista arbitrada con frecuencia bienal, que contiene ocho artículos, producto de investigaciones procedentes de distintos ámbitos universitarios tanto a nivel nacional como internacional, y una reseña sobre un libro publicado de forma reciente. Todos los artículos aquí publicados han pasado por un riguroso sistema de arbitraje lo cual nos permiten continuar haciendo posible la publicación de artículos de calidad científica de actualidad.

Tenemos el agrado de informar que a partir del número 3 la presente revista forma parte de la base internacional de Latindex, que se trata de un sistema de Información sobre las revistas de investigación científica, técnico-profesionales y de divulgación científica y cultural que se editan en los países de América Latina, el Caribe, España y Portugal -cumpliendo con todos sus requisitos de evaluación-.

El próximo reto de nuestra revista -la cual viene generando un espacio académico para difundir conocimiento científico sobre las Ciencias de la Educación tanto a nivel nacional, regional como internacional producido por expertos en sus respectivas áreas de estudio- es el de ingresar en otras bases de revistas científicas de soporte papel y también electrónico de prestigio internacional. 